\title{
Insulin Use in Diabetic Hyperglycemic Emergencies: A Narrative from Benin City, Nigeria
}

Ezeani Ignatius Ugochukwu' ${ }^{1 *}$, Chukwuonye Innocent ljezie ${ }^{2}$, Okwuonu Godswill C ${ }^{2}$, Ohagwu Kenneth Arinze ${ }^{3}$, Abali Chuku ${ }^{4}$ and Eregie Aihanuwa ${ }^{5}$

${ }^{1}$ Division of Endocrinology, Diabetes and Metabolism, Department of Internal Medicine, Federal Medical Center, Umuahia, Abia state, Nigeria

2Division of Nephrology, Department of Internal Medicine, Federal Medical Center, Umuahia, Abia state, Nigeria

${ }^{3}$ Department of Internal Medicine, Federal Medical Center, Umuahia, Abia state, Nigeria

${ }^{4}$ Department of Ophthalmology, Federal Medical Center, Umuahia, Abia state, Nigeria

${ }^{5}$ Department of Internal Medicine, University of Benin Teaching Hospital, Benin City, Edo state, Nigeria

\begin{abstract}
Objective: The primary objective of this study is to determine the types of hyperglycaemic emergencies (HEs) seen in UBTH. The secondary objective is to assess the amount of regular insulin used in various HEs within the first 24 hours to reduce hyperglycaemia (AI24HR), amount of regular insulin used in various HEs to reduce blood glucose level to less than $250 \mathrm{mg} / \mathrm{dL}$ (AITRH), and time (in hours) to resolve hyperglycaemia (TRH).

Methodology: A total of 105 patients admitted to A\&E unit for HEs were included in the study. This was a prospective, longitudinal study in which patients admitted to A\&E unit who fulfilled the criteria for HEs were selected using a non-probability sampling technique. Data obtained was analyzed using SPSS version 15 . Test statistics used were chi-squared test, student t-test and analysis of variance (ANOVA) while $p$-value was set at less than or equal to 0.05 .

Results: Types of HEs found in this study include diabetic ketoacidosis (DKA) seen in $28 \%$ of patients, hyperosmolar hyperglycaemic non ketotic state (HHNK) seen in 50\%, normo-osmolar non ketotic hyperglycaemic state (NNHS) in 12\%, and mixed diabetic ketoacidosis/hyperosmolar hyperglycaemic non ketotic state (DKA/HHNK) seen in $10 \%$ of patients. The mean (SD) AITRH in patients that presented with DKA, HHNK, NNHS and Mixed HE were $38.48 \pm 15.40,65.81 \pm 15.88,53.84 \pm 15.48,62.80 \pm 12.26$ units respectively. Similarly, the mean (SD) Al24HR in patients with DKA, HHNK, NNHS and Mixed HE were $73.17 \pm 20.94,113.4 \pm 26.81,88.31 \pm 16.52,103.0 \pm 17.75$ units respectively. The TRH in patients that presented with DKA, HHNK, NNHS and Mixed HE were $5.64 \pm 4.7,5.82$ $\pm 3.1,5.74 \pm 2.7,5.12 \pm 2.24$ hours respectively. There was statistically significant difference in Al24HR and AITRH in various types of HEs. However, there was no significant difference in TRH.
\end{abstract}

Conclusion: Patients with HHNK constituted the highest number of subjects and they require more regular insulin than patients with other types of HEs.

Keywords: Hyperglycaemia; Emergency; Diabetes mellitus; Regular insulin; Plasma glucose

\section{Introduction}

Hyperglycaemic emergencies (HE) such as DKA and HHNK state are acute complications of diabetes mellitus (DM). They are the most serious acute metabolic complications of DM and are associated with mortality. These disorders are associated with absolute or relative insulin deficiency, volume depletion, and electrolyte and acidbase abnormalities [1]. Both disorders are associated with serious complications if not promptly diagnosed and treated. Successful treatment also requires search for the precipitating causes [2]. Although DKA and HHNK have been described as distinct entities, one third of patients exhibit findings of both conditions [3].

In Nigeria, HEs are important causes of morbidity and mortality. This is due to poor drug compliance secondary to poverty, poor health education, infection, delayed diagnosis and treatment, lack of access to medical care, erratic supply of essential drugs, cultural and religious beliefs, poor laboratory support and less emphasis on electrolyte monitoring especially potassium [4-9].

The cardinal principles of management of HEs include [10]: replacement of deficient insulin, replacement of fluid losses, correction of electrolyte imbalances, and restoration of acid-base balance, identifying and treating precipitating cause. Insulin therapy is the cornerstone of management of HEs [3]. Insulin inhibits lipolysis, ketogenesis and gluconeogenesis in addition to improving extrahepatic utilization of glucose and ketone bodies [1]. It also restores normal transmembrane electrolyte balance [5]. Although there are many studies that have reported treatment of HEs, few studies have highlighted the amount and rate of insulin used and its effect on the rate of plasma glucose (PG) decrease. The primary objective of this study is to determine the types of hyperglycaemic emergencies (HEs) seen in UBTH. The secondary objective is to assess the amount of regular insulin used in the various HEs within the first 24 hours to reduce hyperglycaemia (AI24HR), the total amount of regular insulin used to reduce blood glucose level to less than $250 \mathrm{mg} / \mathrm{dL}$ (AITRH), and the time (in hours) to resolve hyperglycaemia (TRH).

${ }^{*}$ Corresponding author: Dr Ezeani IU (MBBS, FMCP), Department of Medicine Federal Medical Center, P.M.B 7001, Umuahia, Abia state, Nigeria, Tel: +2348060692131; E-mail: ignatiusez@yahoo.com

Received June 26, 2015; Accepted July 22, 2015; Published July 27, 2015

Citation: Ugochukwu El, ljezie Cl, Godswill CO, Arinze OK, Chuku A, et al. (2015) Insulin Use in Diabetic Hyperglycemic Emergencies: A Narrative from Benin City, Nigeria. J Diabetes Metab 6: 585. doi:10.4172/2155-6156.1000585

Copyright: (ㅇ 2015 Ugochukwu El, et al. This is an open-access article distributed under the terms of the Creative Commons Attribution License, which permits unrestricted use, distribution, and reproduction in any medium, provided the original author and source are credited. 
Citation: Ugochukwu El, ljezie CI, Godswill CO, Arinze OK, Chuku A, et al. (2015) Insulin Use in Diabetic Hyperglycemic Emergencies: A Narrative from Benin City, Nigeria. J Diabetes Metab 6: 585. doi:10.4172/2155-6156.1000585

\section{Methodology}

This prospective study was conducted in a 500-bed federal government tertiary hospital. Subjects recruited for this study were admitted at the Accident and Emergency unit for HE.

i. The inclusion criteria are patients 18 years and older with DM (known or newly diagnosed) meeting the diagnostic criteria for the hyperglycaemic emergencies DKA, HHNK and NNHS. DKA diagnostic criteria includes random $\mathrm{PG}>17 \mathrm{mmol} / \mathrm{L}(300 \mathrm{mg} / \mathrm{dL})$, ketonuria of $2+$ (define ketonuria $2+$ when used for the first time here) or more (ketonuria of $2+$ implies presence of significant ketones in urine) and serum bicarbonate of less than $18 \mathrm{mmol} / \mathrm{L}$ $[11,12]$. HHNK diagnostic criteria include random $P G>25$ $\mathrm{mmol} / \mathrm{L}(450 \mathrm{mg} / \mathrm{dL})$ and plasma osmolality $>320 \mathrm{mosmol} / \mathrm{L}$ with insignificant ketonuria [12,13]; NNHS diagnostic criteria include random $\mathrm{PG}>17 \mathrm{mmol} / \mathrm{L}(300 \mathrm{mg} / \mathrm{dL})$, serum osmolality $<320$ mosmol/L and absent or minimal $(1+)$ ketonuria [12,13]. Mixed DKA and HHNK is based on PG $>300 \mathrm{mg} / \mathrm{dL}$, serum bicarbonate level $<15 \mathrm{mmol} / \mathrm{l}$ and ketonuria of $2+$ or more $[3,14]$.

The exclusion criteria are-pregnancy, patients with end stage renal disease (ESRD), congestive heart failure (CHF), hepatic failure, and anasarca.

The study was approved by the Ethics and Research committee of the institution.

One hundred and five patients meeting the inclusion criteria were enrolled into the study (Table 1).

On presentation, a diagnosis of HE was made. Therapy was

Table 1: Comparison of the distribution of hyperglycaemic emergencies by demographic parameters.

\begin{tabular}{|c|c|c|c|c|c|c|c|}
\hline Parameter & $\begin{array}{l}\text { DKA } \\
n=29\end{array}$ & $\begin{array}{c}\text { HHNK } \\
n=53\end{array}$ & $\begin{array}{c}\text { NNHS } \\
n=13\end{array}$ & $\begin{array}{c}\text { Mixed } \\
n=10\end{array}$ & $\mathbf{X}^{2}$ & df & $\mathbf{P}$ \\
\hline $\begin{array}{l}\text { Age Group (Years) } \\
20-29 \\
30-39 \\
40-49 \\
50-59 \\
60-69 \\
70-79 \\
80-89\end{array}$ & $\begin{array}{l}9 \\
4 \\
3 \\
7 \\
5 \\
1 \\
0\end{array}$ & $\begin{array}{c}0 \\
4 \\
8 \\
13 \\
17 \\
8 \\
3\end{array}$ & $\begin{array}{l}0 \\
2 \\
1 \\
5 \\
3 \\
1 \\
1\end{array}$ & $\begin{array}{l}0 \\
2 \\
0 \\
3 \\
2 \\
2 \\
1\end{array}$ & 35.21 & 18 & 0.01 \\
\hline $\begin{array}{l}\text { Sex } \\
\text { Male } \\
\text { Female }\end{array}$ & $\begin{array}{l}13 \\
16\end{array}$ & $\begin{array}{l}25 \\
28\end{array}$ & $\begin{array}{l}8 \\
5\end{array}$ & $\begin{array}{l}7 \\
3\end{array}$ & 2.76 & 3 & 0.43 \\
\hline $\begin{array}{l}\text { Marital Status } \\
\text { Single } \\
\text { Married } \\
\text { Divorced } \\
\text { Widow/Widower }\end{array}$ & $\begin{array}{c}8 \\
16 \\
0 \\
5\end{array}$ & $\begin{array}{c}2 \\
42 \\
0 \\
9\end{array}$ & $\begin{array}{c}1 \\
10 \\
1 \\
1\end{array}$ & $\begin{array}{l}1 \\
7 \\
0 \\
2\end{array}$ & 18.89 & 9 & 0.03 \\
\hline $\begin{array}{l}\text { Level Of Education } \\
\text { No Education } \\
\text { Primary } \\
\text { Secondary } \\
\text { Tertiary }\end{array}$ & $\begin{array}{c}1 \\
5 \\
12 \\
11\end{array}$ & $\begin{array}{c}4 \\
16 \\
19 \\
14\end{array}$ & $\begin{array}{l}1 \\
3 \\
2 \\
5\end{array}$ & $\begin{array}{l}1 \\
3 \\
3 \\
3\end{array}$ & 4.81 & 9 & 0.85 \\
\hline $\begin{array}{l}\text { Smoking } \\
\text { Yes } \\
\text { No }\end{array}$ & $\begin{array}{c}2 \\
27\end{array}$ & $\begin{array}{c}5 \\
48\end{array}$ & $\begin{array}{c}0 \\
13\end{array}$ & $\begin{array}{c}0 \\
10\end{array}$ & 2.29 & 3 & 0.51 \\
\hline $\begin{array}{l}\text { Alcohol Use } \\
\text { Yes } \\
\text { No }\end{array}$ & $\begin{array}{c}28 \\
1\end{array}$ & $\begin{array}{c}53 \\
0\end{array}$ & $\begin{array}{c}0 \\
13\end{array}$ & $\begin{array}{c}0 \\
10\end{array}$ & 2.30 & 3 & 0.52 \\
\hline
\end{tabular}

DKA=Diabetic ketoacidosis, $\mathrm{HHNK}=$ Hyperosmolar hyperglycaemic non ketotic state, NNHS=Normo osmolar non ketotic hyperglycaemic state, Mixed DKA/ $\mathrm{HHNK}=$ Mixed diabetic ketoacidosis hyperglycaemic hyperosmolar non ketotic state, $D M=$ Diabetes mellitus, $X^{2}=$ chi-square, $d f=$ degree of freedom, $p=p$-value initiated using the outline for the management of HE (as in appendix I). Intravenous fluid replacement was given using isotonic saline and subsequently, $5 \%$ dextrose saline when blood sugar was less than 250 $\mathrm{mg} / \mathrm{dL}$ or $13.8 \mathrm{mmol} / \mathrm{L}$ at the rate of 0.025 units/minute.

A total of 20 units of regular insulin (10 units intravenously (IV) and 10 units intramuscularly (IM) both as initial doses) was given followed by 6 units IV every hour until blood glucose levels decreased to less than $250 \mathrm{mg} / \mathrm{L}(13.8 \mathrm{mmol} / \mathrm{L})$. Six units of regular insulin was subsequently added to each $500 \mathrm{~mL}$ of dextrose-saline infusion to run 4hourly at a rate of 0.025 units/minute. Potassium $\left(\mathrm{K}^{+}\right)$replacement was initiated in non-hyperkalemic patients making at least $30 \mathrm{mls} / \mathrm{hr}$ of urine. For serum $\mathrm{K}^{+}$less than $3.5 \mathrm{mmol} / \mathrm{L} 40 \mathrm{mmol}$ of potassium chloride $(\mathrm{KCl})$ was added to each liter of $5 \%$ dextrose- normal saline. For serum $\mathrm{K}^{+}$between $3.5-5.5 \mathrm{mmol} / \mathrm{L}, 20 \mathrm{mmol}$ of $\mathrm{KCl}$ was added and for $\mathrm{K}^{+}$greater than $5.5 \mathrm{mmol} / \mathrm{L} \mathrm{KCl}$ was withheld.

Capillary and venous blood glucose levels were monitored. Capillary blood glucose using glucometer was measured every hour while venous blood was measured every 6 hours for the first 24 hours concurrently for comparison. Also, electrolytes (potassium and bicarbonate which ones) were checked at 0,12 and 24 hours. Fluid input and output were also monitored.

Patients were transitioned from IV regular insulin to subcutaneous pre-meal insulin Mixtard at a total daily dose of 0.6-0.8 units/kg/day when able to tolerate oral adequately. Prior to hospital discharge, patients were prescribed oral hypoglycemic agents or insulin. Patients requiring insulin on discharge were taught about insulin dosing, adverse effects, administration and storage. Patients were also taught about life style and dietary modification, importance of regular physical exercises, self-monitoring of blood glucose and need for compliance with drugs and clinic follow-up appointments.

The data obtained was analyzed using the Statistical Package for Social Sciences (SPSS) version 15. Average values of indices studied are expressed as standard deviation (SD) unless otherwise stated. Statistical comparison of proportions was done using chi-squared test. The students t-test was used for comparison of means of two groups while Analysis of variance (ANOVA) was used to compare means of more than two groups. The level of significance was set at a p-value of less than or equal to 0.05 . Serum osmolality was calculated as follows [15-19].

$$
\begin{aligned}
& \text { Serum osmolality }=2\left(\mathrm{Na}^{+}+\mathrm{K}^{+}\right)+\text {Blood Glucose } / 18+\mathrm{BUN} / 2.8 \\
& \text { Normal serum osmolality }=290-320 \mathrm{mosm} / \mathrm{kg} \\
& \text { Anion gap was calculated as follows: }[15] \\
& \text { Anion gap }=\left(\mathrm{Na}^{+}+\mathrm{K}\right)-\left(\mathrm{Cl}^{-}+\mathrm{HCO}_{3}^{-}\right) \\
& \text {Normal anion gap }=10-18 \mathrm{mmol} / \mathrm{L} \text {. }
\end{aligned}
$$

\section{Results}

Three hundred and fifteen patients with diabetes mellitus were evaluated for inclusion in the study. One hundred and nine patients were recruited 105 patients completed the study. Four patients were excluded from the study secondary to incomplete data. Figure 4 shows the pattern of hyperglycaemic emergencies seen in the emergency unit.

Four major diabetic hyperglycaemic emergencies were seen at the emergency unit: HHNK, DKA, MIXED DKA/HHNK and NNHS. The most common HE was HHNK, accounting for 50\% (53) of the subjects, while DKA was seen in $31 \%$ (29), NNHS in 12\% (13) and MIXED 
Citation: Ugochukwu El, ljezie CI, Godswill CO, Arinze OK, Chuku A, et al. (2015) Insulin Use in Diabetic Hyperglycemic Emergencies: A Narrative from Benin City, Nigeria. J Diabetes Metab 6: 585. doi:10.4172/2155-6156.1000585

hyperglycaemic emergency accounted for 7\% (10) of the subjects as shown in Figure 1.

Table 1 shows the comparison of the distribution of HE by demographic parameters. In comparing the demographic features of the subjects in each of the hyperglycaemic emergency groups, no statistically significant difference was observed in the $\operatorname{sex}(\mathrm{p}=0.43)$, level of education $(\mathrm{p}=0.85)$, smoking history $(\mathrm{p}=0.51)$ and alcohol use $(\mathrm{p}=0.52)$. However, there was a statistically significant difference in the age group distribution $(\mathrm{p}=0.01)$ and marital status $(\mathrm{p}=0.03)$. The most common HE seen was HHNK, accounting for $50 \%(n=53)$ of the patients followed by DKA seen in $28 \%(\mathrm{n}=29)$, NNHS $12 \%(\mathrm{n}=13)$ and mixed DKA/HHNK in $10 \%(\mathrm{n}=10)$ of patients.

A comparison of means showed that patients with HHNK had the highest mean age (58.9 \pm 12.3 years) and the lowest mean age (43.4 \pm 16.10 years) was noted in patients with DKA. This difference in age was statistically significant $(\mathrm{p}=0.01)$ (Tables 2 and 3 ).

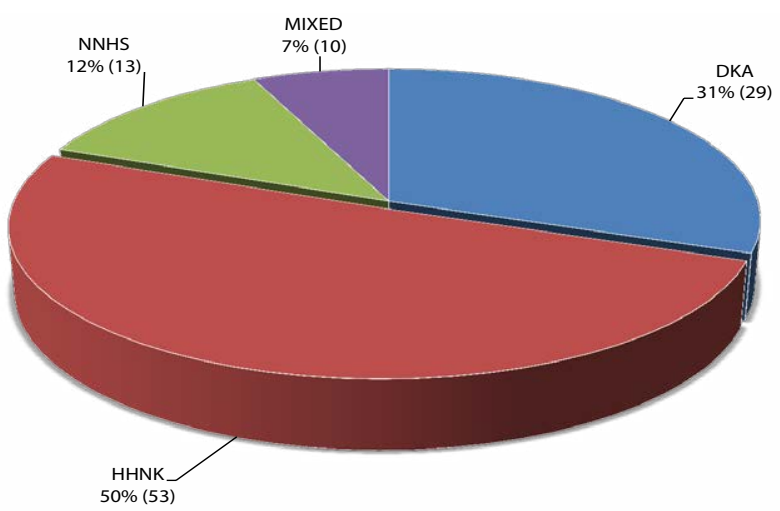

DKA=Diabetic ketoacidosis, HHNK=Hyperosmolar hyperglycaemic non ketotic state, NNHS=Normo osmolar non ketotic hyperglycaemic state, Mixed DKA $\mathrm{HHNK}=$ Mixed diabetic ketoacidosis hyperglycaemic hyperosmolar non ketotic state

Figure 1: Pattern of hyperglycaemic emergencies seen in the emergency unit
A comparison of the doses of insulin used in the various types of hyperglycemic emergencies showed a significant difference in the AITRH and AI24HR ( $p=0.00, p=0.00$ respectively). However there was no significant difference in the TRH ( $\mathrm{p}=0.78)$ (Table 4).

Figure 1 shows the types of hyperglycaemic emergencies seen in $\mathrm{UBTH}$

Figure 2 showing the amount of insulin used according to type of hyperglycaemic emergency reveals that the highest dose of insulin used was in patients with HHNK.

Figure 3 reveals that insulin use increases with the age of the patient.

Figure 4 shows a rate of fall of blood glucose within 24 hours in the various groups of hyperglycemic emergencies.

Figure 5 shows a significant positive correlation between random blood sugar on admission and AI24HR (amount of insulin used within the first 24hours of treatment) $(\mathrm{r}=0.55, \mathrm{p}<0.001)$. Bivariate analysis using linear regression also showed that an additional 0.148 unit of insulin was required in $24 \mathrm{hr}$ to reduce the RBG (random blood glucose) by $1 \mathrm{mg} / \mathrm{dL}$.

Figure 6 shows that the highest mean dose of insulin used to reduce blood glucose to less than $250 \mathrm{mg} / \mathrm{dL}$ (AITRH: amount of insulin needed to reduced hyperglycemia or blood glucose to less than or equal to $250 \mathrm{mg} / \mathrm{dL}$ ) was in patients that presented with HHNK (73.17 units) while the lowest mean dose (38.48 units) was in DKA patients. Similarly, the highest mean dose of insulin used within 24 hours of presentation AI24HR (113.4 units) was in patients with HHNK while the lowest mean dose (65.81 units) was in DKA patients. Table 5 shows that the mean AITRH in patients that presented with DKA, HHNK, NNHS and Mixed HE were $38.48 \pm 15.40,65.81 \pm 15.88,53.84 \pm$ $15.48,62.80 \pm 12.26$ units respectively. Similarly, the mean AI24HR in patients with DKA, HHNK, NNHS and Mixed HE were $73.17 \pm 20.94$, $113.4 \pm 26.81,88.31 \pm 16.52,103.0 \pm 17.75$ units respectively. The mean TRH in patients that presented with DKA, HHNK, NNHS and Mixed HE were $5.64 \pm 4.7,5.82 \pm 3.1,5.74 \pm 2.7,5.12 \pm 2.24$ hours respectively.

\begin{tabular}{|c|c|c|c|c|c|c|c|}
\hline Parameter & DKA $n=29$ Mean \pm SD & HHNK $n=53$ Mean \pm SD & NNHS $n=13$ Mean \pm SD & Mixed $n=10$ Mean \pm SD & $\mathbf{F}$ & df & p \\
\hline Age (Years) & $43.4 \pm 16.10$ & $58.9 \pm 12.30$ & $58.1 \pm 14.32$ & $57.2 \pm 16.41$ & 8.14 & 3 & 0.01 \\
\hline BMI $\left(\mathrm{kgm}^{-2}\right)$ & $27.1 \pm 5.40$ & $28.8 \pm 2.88$ & $28.0 \pm 2.23$ & $28.8 \pm 2.88$ & 1.00 & 3 & 0.40 \\
\hline WC (cm) & $96.1 \pm 15.11$ & $100.4 \pm 12.19$ & $99.2 \pm 10.52$ & $101.7 \pm 6.08$ & 0.89 & 3 & 0.45 \\
\hline WHR & $1.0 \pm 0.07$ & $1.0 \pm 0.07$ & $1.0 \pm 0.06$ & \pm 0.07 & 0.01 & 3 & 1.00 \\
\hline SBP $(\mathrm{mmHg})$ & $131.5 \pm 25.68$ & $140.3 \pm 21.88$ & $125.1 \pm 19.53$ & $129.2 \pm 13.37$ & 1.63 & 3 & 0.19 \\
\hline $\mathrm{DBP}(\mathrm{mmHg})$ & $82.1 \pm 14.28$ & $88.0 \pm 11.63$ & $77.3 \pm 19.54$ & $77.8 \pm 7.86$ & 3.86 & 3 & 0.01 \\
\hline
\end{tabular}

HHNK=Hyperosmolar hyperglycaemic non ketotic state, DKA=Diabetic ketoacidosis, SD=Standard deviation, BMI=Body mass index, WC=Waist circumference,

WHR=Waist hip ratio, $\mathrm{SBP}=$ Systolic blood pressure, $\mathrm{DBP}=$ Diastolic blood pressure, NNHS=Normo osmolar non ketotic hyperglycemic state, Mixed DKA/HHNK=Mixed diabetic ketoacidosis hyperglycemic hyperosmolar non ketotic state

Table 2: Comparison of means of clinical parameters of subjects with hyperglycaemic emergencies using analysis of variance.

\begin{tabular}{|c|c|c|c|c|c|c|c|}
\hline Parameter & DKA $n=29$ Mean \pm SD & HHNK $n=53$ Mean \pm SD & NNHS $n=13$ Mean \pm SD & MIXED $n=10$ Mean \pm SD & $\mathbf{F}$ & df & $\mathbf{P}$ \\
\hline HbA1c (\%) & $8.5 \pm 0.28$ & $8.1 \pm 0.16$ & $7.9 \pm 0.44$ & $9.0 \pm 0.47$ & 1.78 & 3 & 0.16 \\
\hline $\begin{array}{l}\text { RBS on admission } \\
\text { (mg/dl) }\end{array}$ & $439.8 \pm 98.29$ & $611.4 \pm 68.11$ & $505.1 \pm 116.72$ & $596.8 \pm 67.72$ & 28.18 & 3 & 0.01 \\
\hline $\begin{array}{l}\text { Anion Gap } \\
(\mathrm{mmol} / \mathrm{L})\end{array}$ & $24.2 \pm 3.91$ & $14.7 \pm 1.56$ & $14.1 \pm 2.11$ & $25.3 \pm 6.29$ & 83.93 & 3 & 0.01 \\
\hline Serum Osmolality (mOsmol/L) & $303.9 \pm 75.91$ & $335.8 \pm 97.44$ & $312.6 \pm 51.42$ & $331.1 \pm 81.44$ & 96.04 & 3 & 0.01 \\
\hline FBS on discharge (mg/dl) & $102.9 \pm 12.77$ & $109.0 \pm 11.63$ & $104.2 \pm 12.02$ & $106.1 \pm 9.00$ & 1.86 & 3 & 0.14 \\
\hline
\end{tabular}

$\mathrm{HbA1c}=$ Glycosylated hemoglobin, RBS=Random blood sugar, FBS=Fasting blood sugar, DKA=Diabetic ketoacidosis, HHNK=Hyperosmolar hyperglycemic non ketotic state, NNHS=Normo osmolar non ketotic hyperglycemic state, Mixed DKA/HHNK=Mixed diabetic ketoacidosis hyperglycemic hyperosmolar non ketotic state, df=degree of freedom, $\mathrm{SD}=$ standard deviation

Table 3: Comparison of means HBA1C, RBS, FBS, anion gap and osmoloality of subjects with hyperglycaemic emergencies using analysis of variance. 
Citation: Ugochukwu El, ljezie Cl, Godswill CO, Arinze OK, Chuku A, et al. (2015) Insulin Use in Diabetic Hyperglycemic Emergencies: A Narrative from Benin City, Nigeria. J Diabetes Metab 6: 585. doi:10.4172/2155-6156.1000585

Page 4 of 6

\begin{tabular}{|l|c|c|c|c|c|}
\hline Parameter & $\begin{array}{c}\text { Male } \\
\text { n=53 Mean } \pm \text { SD }\end{array}$ & $\begin{array}{c}\text { Female } \\
\text { n=52 Mean } \pm \text { SD }\end{array}$ & $\mathbf{t}$ & df & $\mathbf{p}$ \\
\hline AlTRH(units) & $56.9 \pm 18.9$ & $56.1 \pm 19.7$ & 0.05 & 103 & 0.83 \\
\hline Al 24HR (units) & $98.3 \pm 28.1$ & $98.1 \pm 30.2$ & 0.04 & 103 & 0.97 \\
\hline TRH (hours) & $5.5 \pm 1.7$ & $5.5 \pm 2.1$ & 0.08 & 103 & 0.94 \\
\hline
\end{tabular}

Al $24 \mathrm{HR}=$ Amount of insulin in units used within 24hours of admission, $\mathrm{TRH}=\mathrm{Time}$ in hours to resolve hyperglycemia, AITRH=Amount of insulin in units used to reduce blood sugar to $\leq 250 \mathrm{mg} / \mathrm{dl}, \mathrm{SD}=$ Standard deviation, $\mathrm{df}=$ degree of freedom, $\mathrm{p}=\mathrm{p}$-value

Table 4: Comparison of doses of insulin therapy used according to sex.

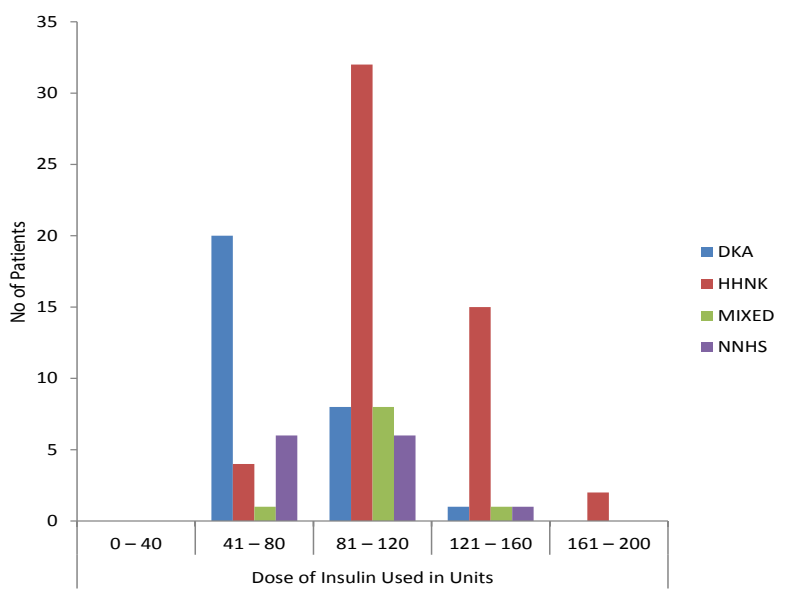

DKA=Diabetic ketoacidosis, HHNK=Hyperosmolar hyperglycemic non ketotic state, NNHS=Normo osmolar non ketotic hyperglycemic state, Mixed DKA/HHNK=Mixed diabetic ketoacidosis/hyperglycemic hyperosmolar non ketotic state

Figure 2: Cord blood (CB) levels of F2-Isoprostanes (F2-IsoPs) in large (LGA), small (SGA) or appropriate for gestational age newborns in a combined group (normal and overweight or obese women).

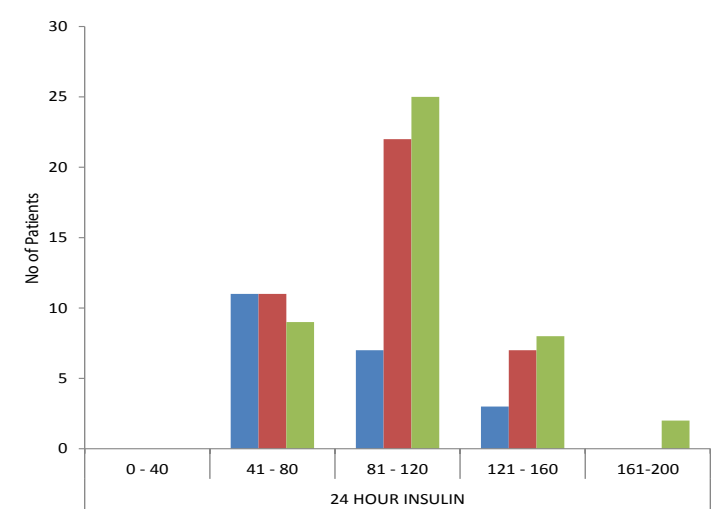

Figure 3: The amount of insulin used according to age.

\section{Discussion}

Hyperglycaemic emergencies (HEs) are acute complications of diabetes mellitus with a projected increase in incidence. The objective of this study is to determine the types of HEs seen in UBTH and assess the amount of regular insulin used (in the first 24 hours and total regular insulin) to reduce blood glucose level to less than $250 \mathrm{mg} / \mathrm{dL}$ in the treatment of various HEs.

The most common HE seen in this study was HHNK (50\%). The

prevalence of DKA was $28 \%$ followed by NNHS at $12 \%$ and mixed DKA/HHNK at $10 \%$. Patients with HHNK had the highest mean (SD) age of 58.9 (1.69) years similar to findings from other studies $[11,13,20]$. The mean (SD) age was 43.4 years in patients with diabetic ketoacidosis, a finding also similar to the occurrence of DKA in older subjects noted by Ehusani [11], Ogbera et al. [20], Okoro et al. [21] and Adesina [22]. Nine (31\%) of the patients with DKA were under 30 years and had type $1 \mathrm{DM}$; which presents at a younger age [1]. The prevalence of NNHS was $12 \%$ with a mean (SD) age of 58.1 (14.32) years. These patients presented with hyperglycaemia with normal serum osmolarity and absent or minimal acidosis. This is comparable with findings by Rolfe et al. [13] who also reported a prevalence of $19 \%$ in Johannesburg, South Africa. Ehusani [11] and Adesina [12] reported a prevalence of $34.4 \%$ and $30 \%$ respectively in the same patient population. The possible explanation for this varied presentation is that hyperglycaemic emergencies present as a "spectrum" and NNHS presents along the spectrum with HHNK prevailing as osmotic diuresis worsens. Mixed

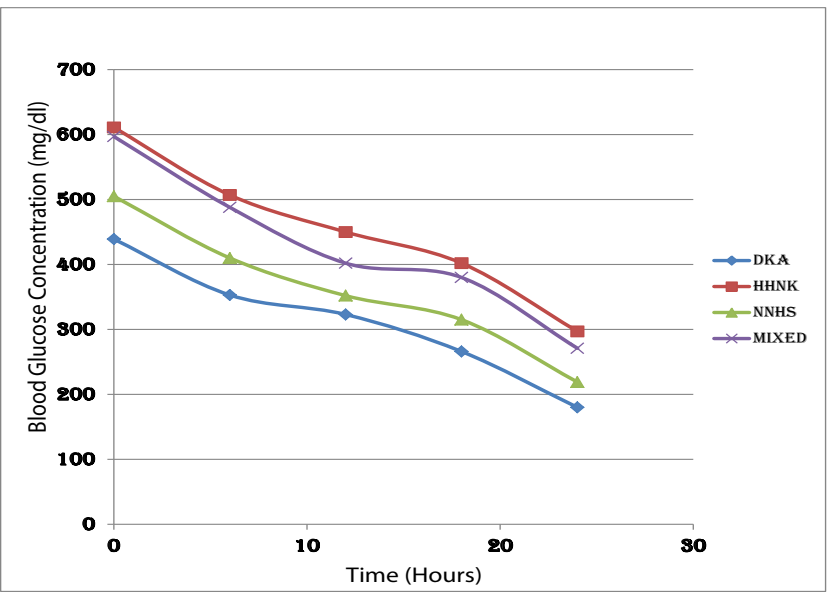

DKA=Diabetic ketoacidosis, HHNK=Hyperosmolar hyperglycemic non ketotic state, NNHS=Normo osmolar non ketotic hyperglycemic state, Mixed $\mathrm{DKA} / \mathrm{HHNK}=$ Mixed diabetic ketoacidosis/hyperglycemic hyperosmolar non ketotic state

Figure 4: Rate of fall of blood glucose within the first 24 hours in the various groups of hyperglycaemic emergencies.

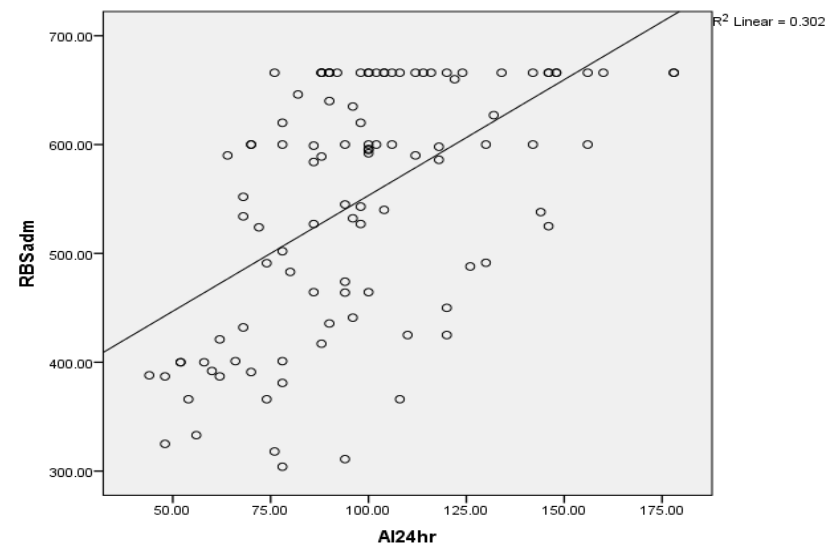

Rbs adm=random blood sugar on admission, Al24hr=Amount of insulin in units used within 24 hours of treatment

Figure 5: A correlation between RBG on admission and AI24HR and bivariate analysis using linear regression to determine the amount of insulin required in 24 hours to reduce RBG by $1 \mathrm{mg} / \mathrm{dL}$. 
DKA/HHNK was found in $10 \%$ of patients. The mean (SD) age of this group was 57.2 (16.4) years, a findings similar to studies by Ehusani [11], Mac Isaac et al. [12], Wachtel et al. [23] and Adesina [22] who reported a mixed picture of hyperglycaemic emergencies in a subset of patients in their various studies (Include prevalence \% from these studies if available similar to line 23 above).

The mean plasma glucose at presentation was $549 \mathrm{mg} / \mathrm{dL}$ (range of $304 \mathrm{mg} / \mathrm{dL}$ to $660 \mathrm{mg} / \mathrm{dL}$ ). The mean plasma glucose (SD) was highest in the HHNK group at 611.4 (68.11). Diabetic ketoacidosis had the lowest mean plasma glucose of $439.8 \mathrm{mg} / \mathrm{dL}$ (98.29). These findings are similar to the publication by Ehusani [11] and Rolfe et al. [13] which reported the highest mean plasma glucose at presentation in the HHNK group.

Nineteen subjects (18\%) with hyperglycaemic emergency presented with diagnosis of DM for the first time. This finding is consistent with the reports from the study done by Ehusani [11], Ogbera et al. [20] and Adesina [22] who reported prevalence rates of newly diagnosed DM of $13.3 \%, 15 \%$ and $46 \%$, respectively. Another study done by Pepper et al. [24] in South Africa reported a prevalence of $11 \%$. A previously undiagnosed diabetic presenting for the first time with hyperglycaemic emergency is a documented mode of presentation and this could be due to ignorance of the symptoms of diabetes which eventually leads to late presentation.

\section{Amount of insulin used in the treatment of hyperglycemic emergencies}

There is significant difference $(\mathrm{p}<0.05)$ in the amount of insulin required in the various types of hyperglycaemic emergencies. Patients with HHNK require more insulin than patients with other types of hyperglycaemic emergencies. This is not unexpected since patients with HHNK generally present with a higher mean blood glucose

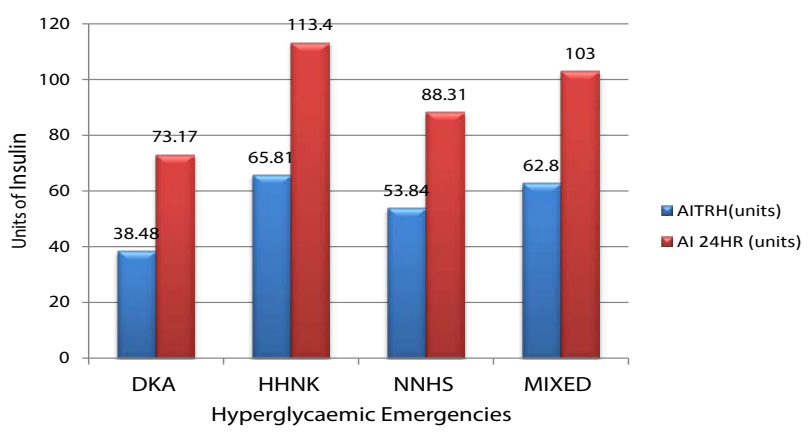

Al $24 \mathrm{HR}=$ Amount of insulin in units used within 24 hours of admission, AITRH=Amount of insulin in units used to reduce blood glucose to $\leq 250 \mathrm{mg} /$ dl, DKA=Diabetic ketoacidosis, HHNK=Hyperosmolar hyperglycemic non ketotic state, NNHS=Normo osmolar non ketotic hyperglycemic state, Mixed DKA/HHNK=Mixed diabetic ketoacidosis/hyperglycemic hyperosmolar non ketotic state

Figure 6: The mean dose of insulin used according to the various hyperglycaemic emergencies. compared with subjects with other types of HEs. The amount of insulin used within the first 24 hours of presentation was highest in subjects with HHNK.

Interestingly, there is no significant difference between insulin dose and age of patient $(\mathrm{P}>0.05)$ although patients more than 55 years required more insulin dose suggesting that insulin requirement increases with age. Patients less than 35 years require the least amount of insulin within the first 24 hours to reduce hyperglycaemia.

There was no significant difference in the amount of insulin used to resolve hyperglycemia (AITRH) $(\mathrm{p}=0.83)$, time to resolve hyperglycemia (TRH) $(\mathrm{p}>0.94)$ and amount of insulin used in 24 hours between male and female groups (AI24HR) $(\mathrm{p}=0.97)$. There was no significant difference in the mean dose of insulin between male and female patients $(p>0.05)$. Reasons for this similarity in insulin dosage are unclear; however a study by Lois Jovanovik [25] reported a higher insulin dose in men compared with women as a result of insulin resistance. Reasons for this difference was that men were reported to have more lean mass and women to have higher adiposity. Men were also found to have more visceral and hepatic adipose tissue, whereas women had more peripheral or subcutaneous adipose tissue. The author concluded that these differences, as well as differences in sex hormones and adipokines, may contribute to a more insulin sensitive environment in women than in men. However, effect was not observed in our study. A major strength of this study is that it was the first study in Benin City that specifically looked at the dose of insulin and its effect on the rate of blood glucose decrease in the various hyperglycaemic emergencies: to the best of our knowledge, there has not been any previous study on this interesting group of subjects. A major limitation of the study is the inability to assess, serum lactate and serum $\mathrm{pH}$. This was a small study therefore a larger and specifically designed study is needed to assess the amount of insulin needed to reduce hyperglycaemia in patients with hyperglycaemic emergencies.

Based on the results of this study, we recommend healthcare facilities be equipped with appropriate laboratory equipment in addition to manpower training and development. This will enable close monitoring of biochemical indices especially electrolytes of patients with HEs with a view to diagnosing the different HEs and prompt treatment with insulin reducing morbidity and mortality. The National Health Insurance policy should be strengthened and implemented in order to assist the poor and socially disadvantaged in the society (including those at risk of hyperglycaemic emergency) in procuring insulin and receiving quality healthcare.

\section{Conclusion}

The mean plasma glucose was highest in the HHNK group. Patients with DKA had the lowest mean plasma glucose. Patients with HHNK require higher insulin doses than other HE groups with insulin requirement increasing with age. There was significant difference in AI24HR, AITRH while there was no significant difference in TRH among the various HEs.

\begin{tabular}{|c|c|c|c|c|c|c|c|}
\hline & DKA $n=29$ Mean \pm SD & HHNK $n=53$ Mean \pm SD & NNHS $n=13$ Mean \pm SD & Mixed $n=10$ Mean \pm SD & $\mathbf{F}$ & df & $p$ \\
\hline AITRH (Units) & $38.48 \pm 15.40$ & $65.81 \pm 15.88$ & $53.84 \pm 15.48$ & $62.80 \pm 12.26$ & 20.4 & 3 & 0.00 \\
\hline Al 24HR (units) & $73.17 \pm 20.94$ & $113.4 \pm 26.81$ & $88.31 \pm 16.52$ & $103.0 \pm 17.75$ & 19.26 & 3 & 0.00 \\
\hline TRH (hours) & $5.64 \pm 4.7$ & $5.82 \pm 3.1$ & $5.74 \pm 2.7$ & $5.12 \pm 2.24$ & 11.22 & 3 & 0.78 \\
\hline
\end{tabular}

Al $24 \mathrm{HR}=$ Amount of insulin in units used within 24 hours of admission, $\mathrm{TRH}=$ Time in hours to resolve hyperglycemia, AITRH=Amount of insulin in units used to reduce blood sugar to $\leq 250 \mathrm{mg} / \mathrm{dl}$, df=degree of freedom, $\mathrm{p}=\mathrm{p}$-value. DKA=Diabetic ketoacidosis, HHNK=Hyperosmolar hyperglycemic non ketotic state, NNHS=Normo osmolar non ketotic hyperglycemic state, Mixed DKA/HHNK=Mixed diabetic ketoacidosis hyperglycemic hyperosmolar non ketotic state, df=degree of freedom

Table 5: Comparison of doses of insulin therapy used according to the various groups of hyperglycemic emergencies. 
Citation: Ugochukwu El, ljezie Cl, Godswill CO, Arinze OK, Chuku A, et al. (2015) Insulin Use in Diabetic Hyperglycemic Emergencies: A Narrative from Benin City, Nigeria. J Diabetes Metab 6: 585. doi:10.4172/2155-6156.1000585

Page 6 of 6

\section{Acknowledgment}

We wish to acknowledge Dr A.E Edo for critically reviewing this manuscript. We also thank members of the department of Internal Medicine, University of Benin Teaching Hospital, Benin City and Federal Medical Center, Umuahia for their support throughout the period of this study.

\section{References}

1. Alvin CP (2005) Diabetes Mellitus: Aetiological classification In: Kasper DL, Braunwald E, Fauci AS, Hauser SL, Longo DL, Jameson JL (eds). Harrison's principles of Internal Medicine (16 ${ }^{\text {th }}$ edtn). Mc Graw Hill (Medical Publishing division) 323: 2153-2179.

2. Eregie A, Unadike BC (2010) Common causes of morbidity and mortality amongst diabetic admissions at the University of Benin Teaching Hospital, Benin City, Nigeria. Pak J Med Res 49: 89-93.

3. Umpierrez GE, Murphy MB, Kitabchi AE (2002) Diabetic Ketoacidosis and Hyperglycaemic Hyperosmolar Syndrome. Diabetes Spectrum 15: 28-36.

4. Ogbera AO, Awobusuyi J, Unachukwu C, Fasanmade O (2009) Clinical features, predictive factors and outcome of hyperglycaemic emergencies in a developing country. BMC Endocr Disord 9: 9

5. Anumah FO (2007) Management of hyperglycaemic emergencies in the tropics. Ann Afr Med 6: 45-50.

6. Anochie I, Nkanginieme KEO (2002) Childhood diabetes in Port Harcourt, Southern Nigeria. Diabetes International. 12: 20-21.

7. Ndububa DA, Erhabor GE (1994) Diabetic mortalities in Ilesa, Nigeria: a retrospective study. Cent Afr J Med 40: 286-289.

8. Talabi AO (2000) Is hypokalemia the killer in Diabetic Hyperosmolar states during treatment? Diabetes International 10: 60-61.

9. Amata AO (1994) Problems and challenges of managing ketoacidosis in tropical developing countries. International Diabetes Digest. 105: 18-21.

10. Slovis CM, Mork VG, Slovis RJ, Bain RP (1987) Diabetic ketoacidosis and infection: leukocyte count and differential as early predictors of serious infection. Am J Emerg Med 5: 1-5.

11. Ehusani FO (2000) Comparative study of intravenous insulin infusion and intermittent intramuscular injection of insulin in the management of hyperglycaemic emergencies. Part 2 FMCP dissertation, National Postgraduate Medical College (NPMC)

12. Maclsaac RJ, Lee LY, McNeil KJ, Tsalamandris C, Jerums G (2002) Influence of age on the presentation and outcome of acidotic and hyperosmolar diabetic emergencies. Intern Med J 32: 379-385.

13. Rolfe M, Ephraim GG, Lincoln DC, Huddle KR (1995) Hyperosmolar nonketotic diabetic coma as a cause of emergency hyperglycaemic admission to Baragwanath Hospital. S Afr Med J 85: 173-176.

14. Kitabchi AE, Umpierrez GE, Murphy MB, Barrett EJ, Kreisberg RA, et al. (2001) Management of hyperglycemic crises in patients with diabetes. Diabetes Care 24: 131-153.

15. Kumar P, Clark M (2002) Water, electrolysis and acid-base balance. In: Clinical medicine ( $5^{\text {th }}$ edtn). Elsevier Science Limited. 667-699.

16. Veiga F, Fernandes C, Teixeira F (2000) Oral bioavailability and hypoglycaemic activity of tolbutamide/cyclodextrin inclusion complexes. Int J Pharm 202: 165-171.

17. Brownlee M, Aiello LP, Cooper ME, Vinik Al, Nesto RW, et al. (2008) Complications of Diabetes Mellitus In: Kronenberg HM et al (eds). Williams

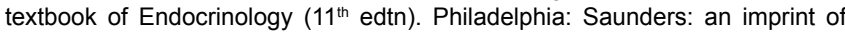
Elsevier Inc. 30: 1329-1416.

18. Umpierrez GE, Kelly JP, Navarrete JE, Casals MM, Kitabchi AE (1997) Hyperglycemic crises in urban blacks. Arch Intern Med 157: 669-675.

19. Kitabchi AE, Umpierrez GE, Murphy MB, Barrett EJ, Kreisberg RA, et al. (2001) Management of hyperglycemic crises in patients with diabetes. Diabetes Care 24: 131-153.

20. Ogbera AO, Awobusuyi J, Unachukwu C, Fasanmade O (2009) Clinical features, predictive factors and outcome of hyperglycaemic emergencies in a developing country. BMC Endocr Disord 9: 9.

21. Okoro EO, Yusuf M, Salawu HO, Oyejola BA (2007) Outcome of diabetic hyperglycaemic emergencies in a Nigerian cohort. Chinese Journal of Medicine.

22. Adesina OF (2008) Comparison of Lispro insulin and regular insulin in the management of hyperglycaemic emergencies. Part 2 FMCP dissertation, National postgraduate Medical College (NPMC).

23. Wachtel TJ, Tetu-Mouradjian LM, Goldman DL, Ellis SE, O'Sullivan PS (1991) Hyperosmolarity and acidosis in diabetes mellitus: a three-year experience in Rhode Island. J Gen Intern Med 6: 495-502.

24. Pepper DJ, Levitt NS, Cleary S, Burch VC (2007) Hyperglycaemic emergency admissions to a secondary-level hospital - an unnecessary financial burden. $S$ Afr Med J 97: 963-967.

25. Jovanovic $L$ (2009) Sex differences in insulin dose and postprandial glucose as BMl increases in patients with type 2 diabetes. Diabetes Care 32: e148. 